\title{
Education efforts may contribute to wider acceptance of human papillomavirus self-sampling
}

This article was published in the following Dove Press journal:

International Journal of Women's Health

2 February 2015

Number of times this article has been viewed

\section{Victoria Crofts ${ }^{1, *}$ \\ Emmanuel Flahault ${ }^{1, *}$ \\ Pierre-Marie Tebeu ${ }^{2}$ \\ Sarah Untiet ${ }^{3}$ \\ Gisèle Kengne Fosso 2 \\ Michel Boulvain ${ }^{3}$ \\ Pierre Vassilakos ${ }^{4}$ \\ Patrick Petignat ${ }^{3}$}

'Faculty of Medicine, University of Geneva, Geneva, Switzerland; ${ }^{2}$ Department of Gynecology and Obstetrics, University Center Hospital, Yaoundé, Cameroon; ${ }^{3}$ Department of Gynecology and Obstetrics, Geneva University Hospitals, Geneva, Switzerland; ${ }^{4}$ Geneva Foundation for Medical Education and Research, Geneva, Switzerland

*These authors contributed equally to this paper
Correspondence: Victoria Crofts Avenue de Miremont 23C, I 206 Geneva, Switzerland Email vickycrofts@yahoo.com
Background: Information about women's acceptance of new screening methods in Sub-Saharan Africa is limited. The aim of this study was to report on women's acceptance of human papillomavirus (HPV) self-sampling following an educational intervention on cervical cancer and HPV.

Methods: Women were recruited from the city of Tiko and a low-income neighborhood of Yaoundé, both in Cameroon. Written and oral instructions about how to perform an unsupervised HPV self-sample were given to participants, who performed the test in a private room. Acceptability of HPV self-sampling was evaluated by questionnaire. Participants previously screened for cervical cancer by a physician were asked additional questions to assess their personal preferences about HPV self-sampling.

Results: A sample of 540 women were prospectively enrolled in the study; median age was 43 years old (range 30-65 years). Participants expressed a high level of acceptance of HPV self-sampling as a screening method following information sessions about cervical cancer and HPV. Most expressed no embarrassment, pain, anxiety, or discomfort (95.6\%, 87.8\%, 91.3\%, and $85.0 \%$, respectively) during the information sessions. Acceptance of the method had no correlation with education, knowledge, age, or socio-professional class. Eighty-six women (16\%) had a history of previous screening; they also reported high acceptance of HPV self-sampling.

Conclusion: Educational interventions on cancer and HPV were associated with high acceptability of HPV self-testing by Cameroonian women. Further evaluation of the intervention in a larger sample and using a control group is recommended.

Keywords: Cameroon women, cervical cancer screening, HPV, low-resource country, physician sampling, self-sampling

\section{Introduction}

Globally, 530,000 new cases of cervical cancer and 275,000 associated deaths were reported in 2008, of which $88 \%$ were diagnosed in developing countries. In Africa alone, 53,000 new cases are reported annually. ${ }^{1}$ Cameroonian data about cervical cancer incidence is poorly investigated, but according to the International Agency for Research on Cancer, the age-standardized incidence rate in 2008 for cervical cancer was estimated at 24 per 100,000, corresponding to 1,474 new cases of cervical cancer. The age-standardized mortality rate that same year was estimated at 17 per 100,000, corresponding to 995 deaths. $^{2}$

Many low-resource countries such as Cameroon have difficulty introducing cervical cancer screening programs due to inadequate material resources, absence of quality control systems, and lack of trained providers. ${ }^{3}$ These conditions have prompted the 
evaluation of simple and inexpensive methods for detecting pre-invasive lesions by visual inspection methods such as visual inspections with acetic acid (VIA) and Lugol's iodine (VILI). Both are inexpensive, relatively simple to perform by trained health care professionals, and can be used as part of a screen-and-treat approach. ${ }^{4}$ However, the sensitivity of these methods is subject to high variability, depending mostly on examiner expertise, and requires quality control. A recent meta-analysis of 77 cross-sectional studies found that sensitivity of VIA in detecting a cervical intraepithelial neoplasia grade 2 (CIN 2) or worse ranged between $14 \%$ and $95 \%$, estimating the pooled sensitivity at $80 \%$. ${ }^{5}$ Based on this and because VIA is not reliable in postmenopausal women, the current (2006) World Health Organization (WHO) Guide to comprehensive cervical cancer control recommends the use of visual inspection methods only in pilot projects and closely monitored settings. ${ }^{4}$

In this context, human papillomavirus (HPV) DNA tests have emerged as a new option for primary cervical cancer screening. They appear to be more sensitive, objective, reliable, and less dependent on investigator competence, than visual inspection. ${ }^{6-9}$ HPV sampling can be performed by patients themselves using the HPV self-test, which supports the idea that HPV self-sampling is a feasible alternative method for primary cervical cancer screening in low-resource settings. ${ }^{10-12}$

The introduction of a new screening method is a complex process, and prior to making it widely available, assessment of its acceptability and women's willingness to perform the test is essential. Studies of women's positions on HPV self-sampling have been conducted in Western countries; it was found that they supported the findings that most women are receptive to HPV self-sampling as part of future screening. ${ }^{13-16}$ To date, only a few studies addressing this issue have been conducted in African women. A previous study conducted in Cameroon by the current authors observed that most women $(62 \%)$ preferred physician sampling to HPV self-sampling, and many did not trust self-sampling methods. ${ }^{17}$ A major concern identified women's beliefs that they did not perform the test properly, and therefore had greater confidence in physician sampling. ${ }^{17}$ In routine screening, this preference manifested as lower participation rates and adherence to screening. Exploratory studies evaluating how to improve confidence in this method are an essential part of the process. The aim of the current study was to assess the acceptance of HPV self-sampling in Cameroonian women following an educational intervention on HPV and cervical cancer.

\section{Methods}

This study was part of a collaborative project organized by the Geneva University Hospitals, the Yaoundé Faculty of Medicine and Biomedical Sciences, and the National Committee for the Fight Against Cancer of Cameroon to promote innovative cervical cancer screening methods and decrease cervical cancer incidence and mortality. The National Ethics Committee of Cameroon for Health Research on Humans approved the study and all participants signed informed consent forms.

\section{Participants}

The study included 540 non-pregnant women between 30 and 65 years of age who had not undergone cervical conization or hysterectomy. Participants were recruited from Tiko, a village in the East Province of Cameroon, using radio, churches, street loudspeakers, and word-of-mouth. In Yaoundé, they were enrolled with the help of a neighborhood hospital, the Centre Hospitalier Dominicain Saint Martin de Porres, through posters and word-of-mouth.

\section{Procedures}

Each session began with a 20 minute lecture during which information about cervical cancer and HPV was provided. This included transmission methods, risk types, relationship between HPV and cervical cancer, and its evolution. Participants received an information sheet containing general information about cervical cancer prevention. Written instructions and explanatory diagrams were provided, and questions about the subject were answered. The main portion of the lecture included a thorough explanation of the disease and instructions on performing HPV self-sampling. Participants then received oral instructions supported by drawings, a sterile flocked swab, and a Copan ESwab $^{\circledR}$ (Copan Italia, Brescia, Italy) transportation tube for self-sampling. The women performed self-sampling alone in a separate calm room where their intimacy was respected. Particular attention was given to ensuring that the women understood that if test results were positive for HPV, they would have to come back for visual inspection and biopsy.

\section{Assessment}

The questionnaire consisted of three parts. The first part included questions to assess socio-demographic data including age, marital status, profession, and education. The second part included questions to evaluate their general knowledge about HPV and cervical cancer. It was scaled as follows: poor knowledge - zero, one, or two correct answers out of four; and good knowledge - three or four correct answers out of 
four. The third part assessed acceptability and preference. Acceptability indices for HPV self-sampling included the following seven items: embarrassment, pain, anxiety, discomfort, complexity, relaxation, and confidence. Each was scored on a 4-point scale ( $1=$ none, $2=$ low, $3=$ moderate, and $4=$ high). A reverse scale was used to rate relaxation and confidence: a low score correlated with high acceptance. A general acceptability score was then generated based on a methodology used in previous studies by adding the mean scores of six of these items. ${ }^{13,18}$ Complexity was excluded from the score because it could not be assessed for physician sampling. An acceptability score was also generated for physician sampling based on participants who had previously undergone screening by a physician.

\section{Statistical analyses}

Differences between the two acceptability scores were evaluated using the Mann-Whitney $U$-test. Chi-square and Fisher's exact tests were used to analyze correlations of preference and acceptance for HPV self-sampling using different variables. These included knowledge, previous history of screening, education, professional class, age, age at first sexual intercourse, and number of lifetime sexual partners. All tests were considered statistically significant when the $P$-value was $<0.05$. Statistical analyses were performed using MS-Excel ${ }^{\circledR}$ (Microsoft Corporation, Redmond, WA, USA) and OpenEpi (version 3.01; www.openepi.com). ${ }^{19}$

\section{Results}

\section{Participants}

All 540 enrolled women completed the process and were included in the analysis; 345 were recruited in Tiko and 195 from a low-income neighborhood of Yaoundé. Mean average age was 43 years old (range $30-65$ years) (Table 1).

\section{HPV self-sampling acceptability}

Participants had a high acceptability score for HPV selfscreening. The majority felt no embarrassment (95.6\%); no pain $(87.8 \%)$; no anxiety $(91.3 \%)$, and no discomfort $(85.0 \%)$. They felt confident that they performed the test correctly $(90.0 \%)$, were relaxed while doing it (84.4\%), and found the test easy to perform $(96.7 \%)$. Additionally, many participants noted that the diagram and written instructions were very helpful. None of the criteria used to evaluate acceptability of HPV self-sampling changed with improved knowledge about HPV and cervical cancer. There was no difference in acceptability scores between participants regarding their level of knowledge (Table 2). In addition, none of
Table I Socio-demographic characteristics of participants $(\mathrm{N}=540)$

\begin{tabular}{ll}
\hline Characteristics & $\mathbf{N}(\%)$ \\
\hline Age (years) & \\
Median & 43 (range 30-65) \\
$30-39$ & $230(42.6)$ \\
$40-49$ & $173(32.0)$ \\
$50-65$ & $137(25.4)$ \\
Marital status & \\
Married/living with a partner & $326(60.4)$ \\
Single & $214(39.6)$ \\
Education & \\
No formal education & $32(5.9)$ \\
Primary & $163(30.2)$ \\
High school & $263(48.7)$ \\
University or other degree & $82(15.2)$ \\
Number of different sexual partners & \\
Mean & $4.3($ range I-30) \\
Age at first sexual intercourse (years) & \\
Mean & $17($ range 6-29) \\
History of previous screening & $86(15.9)$ \\
Yes & $454(84.1)$ \\
No & \\
Knowledge about HPV and cervical cancer & $456(84.4)$ \\
Poor knowledge & $84(15.6)$ \\
Good knowledge & \\
\hline
\end{tabular}

Abbreviation: HPV, human papillomavirus.

the other evaluated variables (education, professional class, age, age at first sexual intercourse, and number of lifetime sexual partners) showed significant impact on HPV selfsampling acceptability. The overall acceptability score for HPV self-sampling was favorable (6.986; Table 3). The score

Table 2 Acceptability according to knowledge and history of previous screening $(\mathrm{N}=540)$

\begin{tabular}{llll}
\hline & $\begin{array}{l}\text { Poor } \\
\text { knowledge } \\
\text { N (\%) }\end{array}$ & $\begin{array}{l}\text { Good } \\
\text { knowledge } \\
\text { N (\%) }\end{array}$ & P-value $^{\text {a }}$ \\
\hline $\begin{array}{l}\text { Embarrassment } \\
\text { Yes }\end{array}$ & $4(0.9)$ & $2(2.4)$ & 0.2 \\
$\begin{array}{l}\text { Pain } \\
\text { Yes }\end{array}$ & $8(1.8)$ & $2(2.4)$ & 0.6 \\
$\begin{array}{l}\text { Anxiety } \\
\text { Yes }\end{array}$ & $6(1.3)$ & $2(2.4)$ & 0.3 \\
$\begin{array}{l}\text { Confidence } \\
\text { Nob }\end{array}$ & $10(2.2)$ & $0(0)$ & 0.3 \\
$\begin{array}{l}\text { Discomfort } \\
\text { Yes }\end{array}$ & $14(3.1)$ & $3(3.6)$ & 0.7 \\
$\begin{array}{l}\text { Relaxation } \\
\text { No }\end{array}$ & $59(12.9)$ & $6(7.1)$ & 0.1 \\
$\begin{array}{l}\text { Complexity } \\
\text { Yes }\end{array}$ & $8(1.8)$ & $0(0)$ & 0.6 \\
\begin{tabular}{l} 
Total \\
\hline Notes:
\end{tabular} & $456(84.4)$ & $84(15.6)$ &
\end{tabular}

Notes: 'Fisher's exact test was used to analyze the results. The test was considered as statistically significant when the $P$-value was $<0.05$; "category "no" includes the answers "none" and "low", category "yes" includes answers "moderate" and "high". 
Table 3 Acceptability scores for individual parameters for selfHPV and physician-HPV

\begin{tabular}{|c|c|c|c|}
\hline & $\begin{array}{l}\text { Self HPV } \\
(n=540)\end{array}$ & $\begin{array}{l}\text { Physician- } \\
\text { sampling } \\
(n=86)\end{array}$ & $P$-value ${ }^{c}$ \\
\hline Embarrassment $^{a}$ & 1.061 & 1.709 & $P<0.001$ \\
\hline Pain $^{\mathrm{a}}$ & 1.143 & 1.860 & $P<0.00$ I \\
\hline Anxiety ${ }^{a}$ & 1.106 & 1.814 & $P<0.00$ I \\
\hline Discomfort $^{\mathrm{a}}$ & 1.196 & 1.744 & $P<0.001$ \\
\hline Relaxation (reverse score) ${ }^{\mathrm{b}}$ & 1.352 & 1.919 & $P<0.001$ \\
\hline Confidence (reverse score) ${ }^{\mathrm{b}}$ & 1.128 & 1.105 & $P=0.91$ \\
\hline Total acceptability score & 6.986 & 10.151 & \\
\hline
\end{tabular}

Notes: al: none; 2: low; 3: moderate; 4: high; bl: high; 2: moderate; 3: low; 4: none; 'Mann-Whitney test was used to analyze the results. The test was considered as statistically significant when the $P$-value was $<0.05$.

Abbreviation: $\mathrm{HPV}$, human papillomavirus.

was based on the sum of all criteria results (embarrassment, pain, anxiety, discomfort, relaxation and confidence). The higher the score, the less it was favorable; the maximum score was 24 .

\section{Comparison of acceptability of HPV self-sampling and physician sampling}

For the 86 women who acknowledged having been previously screened for HPV, HPV self-sampling was rated more favorably than physician sampling for all criteria (Table 3). Participants felt no embarrassment (self: $96.5 \%, \mathrm{n}=83$ versus [vs] physician: $62.8 \%, \mathrm{n}=54$ ); no pain (self: $90.7 \%, \mathrm{n}=78$ vs physician: $46.5 \%, \mathrm{n}=40$ ); no anxiety (self: $93 \%, \mathrm{n}=80$ vs physician: $53.5 \%, \mathrm{n}=46$ ); no discomfort (self: $87.2 \%, \mathrm{n}=75$ vs physician: $54.7 \%, \mathrm{n}=47$ ); and were more relaxed (self: $81.4 \%, \mathrm{n}=70$ vs physician $52.3 \%, \mathrm{n}=45$ ) while performing HPV self-sampling. They felt confident that the screening was properly performed, whether by themselves or by a physician (self: $80.2 \%$ vs physician: 90.7\%).

\section{Preferences according to education, professional class, age, and knowledge}

Asked about their preference for HPV self-sampling or physician-sampling, 14 women stated not having any preference, 64 preferred self-sampling, and eight chose physician sampling. Preference for HPV self-sampling was independent of educational level (no formal or primary education: 10/15; high school education: $38 / 51$; university or other degree: 16/20). Likewise, no significant differences were found between socio-professional classes regarding preference for HPV self-sampling (homemakers: 23/32; employees: 27/37; independent: 12/13; other: 2/4).

\section{Correlation of knowledge for women} with and without previous screening

Women with a previous history of screening had significantly better knowledge about HPV and cervical cancer (26.7\%) than women who had never been screened (13.4\%) $(P=0.003)$.

\section{Discussion}

Cameroon, like most low-income countries, lacks medical and financial resources to implement a cytology-based cervical screening program. ${ }^{2}$ The absence of screening is the main reason why this form of cancer remains a common cause of death among middle-aged women in Cameroon, and represents a major cause of years of life lost to cancer. ${ }^{4}$ There is growing evidence that HPV self-sampling can be an effective alternative for primary cervical cancer screening in low-resource settings. However, implementation of a new screening method is a complex process, and acceptance by the population is an important issue. There are differences among ethnicities, education status, social and marital status, and age. In Western countries, acceptability of HPV self-sampling among racial/ethnic minorities, medically underserved women, and representative population samples has been investigated. These studies did not confirm any influence of cultural differences or religious beliefs on selfsampling. ${ }^{14-16}$

Little published data are available on African women and the acceptability of HPV self-sampling for primary cervical cancer screening. ${ }^{20-22}$ Previous reports revealed that most women were very concerned about diminishing the reliability of the test by performing it incorrectly. These concerns lowered participation rates. ${ }^{23}$ In the current study, information and lectures about cervical cancer and HPV were associated with high acceptance levels for HPV selfsampling. It was observed that information given by a physician about the accuracy of HPV self-sampling had a positive impact on patient anxieties about their ability to perform the test. Participants were specifically asked if they were concerned about incorrectly collecting their own sample; only $1.9 \%$ had this concern. Acceptability of the test was high, regardless of educational level, professional activity, age, and knowledge of HPV and cervical cancer. Many women noted that the diagram and written instructions were very helpful. This information helped reduce the instruction time needed to teach women about HPV self-sampling.

The authors of the current study also observed that, regardless of educational level or age, previously screened women preferred HPV self-sampling to physician sampling. This dif- 
fers from the results of other studies, ${ }^{18,20,23-25}$ as well as that of a previous study conducted by the current authors in Cameroon women. ${ }^{17}$ The latter showed an overall preference for physician sampling, even though HPV self-sampling was well accepted. Confidence remained higher for physician sampling, which could explain why women chose it over HPV self-sampling. Similar to the current study, a previous study by Berner et al also used word-of-mouth advertising as part of their recruitment strategy. The socio-demographic characteristics of the test populations of both studies were very close, with the exception of educational level, which was higher in the Berner study. ${ }^{17}$ The current authors believe that the combination of verbal instructions, diagrams, and answers to questions about HPV and self-sampling provided prior to performing the test could have given women greater confidence in their ability to perform the self-sampling correctly.

Education and information about HPV and cervical cancer was a key point of the current study and an important difference compared to previous studies that provided no educational information about HPV and cervical cancer, and in which screening was given prior to testing and interviewing. ${ }^{17}$

One methodological weakness in the current study was the absence of a control group to evaluate the impact of the educational intervention. Due to this, it was not possible to reach a firm conclusion as to whether the information provided about cervical cancer and HPV was responsible for the high level of acceptance of HPV self-sampling. Moreover, the information given to participants was not standardized; it was provided as personal information. The time and availability of health care workers during this study could be less applicable outside a research setting and not replicable in normal clinical circumstances. Another shortcoming was the recruiting methods used (radio ads, posters, word-ofmouth advertising) that likely resulted in selection bias. It is likely that only those patients who already possessed a high level of acceptance became participants in the study. Finally, the comparison between HPV self-sampling and physician sampling should be interpreted with caution because it was based on personal recollections. Participant impressions of physician sampling may well have changed over time, thereby limiting the validity of the comparison.

Strengths of the study included a large sample size and heterogeneity of the population regarding social and demographic characteristics. Even though the population studied might not have been representative in terms of education of the Cameroonian population as a whole, it nevertheless fitted the profile of the Yaoundé and central region of Cameroon populations. ${ }^{26}$ Finally, this study was one of the first studies to focus on the acceptability of HPV self-sampling in West Africa.

The authors conclude that HPV self-sampling as a primary cervical screening method was deemed acceptable and well received by most of the female population eligible for screening. Education can play a significant role in screening strategies by creating confidence in the method. Further research should concentrate on evaluating large-scale and standardized educational procedures using a control group.

\section{Author contributions}

VC and EF conducted the study and drafted the manuscript, PMT co-designed the study, SU conducted statistical analyses and contributed to the manuscript, GKF conducted the VIA examinations and the follow-up, MB directed the statistical analyses, PV designed the study, and PP co-designed the study and led the research project. All authors contributed toward data analysis, drafting and revising the paper and agree to be accountable for all aspects of the work.

\section{Acknowledgments}

This study was supported by grants from Solidarité Internationale Genève, the University Hospitals of Geneva, Switzerland, and UBS Genève. The authors would like to express their gratitude to the Centre Hospitalier Dominicain Saint Martin De Porres and Sister Cristina for their participation.

\section{Disclosure}

The authors report no conflicts of interest in this work.

\section{References}

1. Ferlay J, Shin HR, Bray F, Forman D, Mathers C, Parkin DM Estimates of worldwide burden of cancer in 2008: GLOBOCAN 2008. Int J Cancer. 2010;127(12):2893-2917.

2. WHO/ICO. Human Papillomavirus and Related Cancers in Cameroon. Summary Report 2012. In Book Human Papillomavirus and Related Cancers in Cameroon. Summary Report 2012.

3. Sankaranarayanan R, Thara S, Esmy PO, Basu P. Cervical cancer: screening and therapeutic perspectives. Med Princ Pract. 2008;17: 351-364.

4. World Health Organization. Comprehensive Cervical Cancer Control: a Guide to Essential Practice. 2006. Available from: http://whqlibdoc. who. int/publications/2006/9241547006_eng.pdf. Accessed April 1, 2012.

5. Sauvaget C, Fayette JM, Muwonge R, Wesley R, Sankaranarayanan R. Accuracy of visual inspection with acetic acid for cervical cancer screening. Int J Gynaecol Obstet. 2011;113(1):14-24.

6. Cuzick J, Clavel C, Petry KU, et al. Overview of the European and North American studies on HPV testing in primary cervical cancer screening. Int J Cancer. 2006;119:1095-1101.

7. Arbyn M, Ronco G, Meijer CJ, Naucler P. Trials comparing cytology with human papillomavirus screening. Lancet Oncol. 2009;10 935-936. 
8. Schiffman M, Wentzensen N, Wacholder S, Kinney W, Gage JC, Castle PE. Human papillomavirus testing in the prevention of cervical cancer. J Natl Cancer Inst. 2011;103:368-383.

9. Ronco G, Giorgi-Rossi P, Carozzi F, et al. Efficacy of human papillomavirus testing for the detection of invasive cervical cancers and cervical intraepithelial neoplasia: a randomised controlled trial. Lancet Oncol. 2010;11:249-257.

10. Zhao FH, Lewkowitz AK, Chen F, et al. Pooled analysis of a self-sampling HPV DNA test as a cervical cancer primary screening method. J Natl Cancer Inst. 2012;104:178-188.

11. Petignat P, Faltin DL, Bruchim I, Tramer MR, Franco EL, Coutlee F. Are self-collected samples comparable to physician-collected cervical specimens for human papillomavirus DNA testing? A systematic review and meta-analysis. Gynecol Oncol. 2007;105:530-535.

12. Franco EL. A new generation of studies of human papillomavirus DNA testing in cervical cancer screening. J Natl Cancer Inst. 2009;101: 1600-1601.

13. Waller J, McCaffery K, Forrest S, et al. Acceptability of unsupervised HPV self-sampling using written instructions. J Med Screen. 2006;13(4):208-213.

14. Forrest S, McCaffery K, Waller J, et al. Attitudes to self-sampling for HPV among Indian, Pakistani, African-Caribbean and white British women in Manchester, UK. J Med Screen. 2004;11(2):85-88.

15. Anhang R, Nelson JA, Telerant R, Chiasson MA, Wright TC Jr. Acceptability of self-collection of specimens for HPV DNA testing in an urban population. $J$ Womens Health (Larchmt). 2005;14: $721-728$.

16. Howard M, Lytwyn A, Lohfeld L, Redwood-Campbell L, Fowler N, Karwalajtys T. Barriers to acceptance of self-sampling for human papillomavirus across ethnolinguistic groups of women. Can J Public Health. 2009;100(5):365-369.

17. Berner A, Ben Hassel S, Tebeu PM, et al. HPV self-sampling in Cameroon: women's uncertainties over the reliability of the method are barriers to acceptance. J Low Genit Tract Dis. 2013;(3):235-241.
18. Dzuba IG, Diaz EY, Allen B, et al. The acceptability of self-collected samples for HPV testing vs the pap test as alternatives in cervical cancer screening. J Womens Health Gend Based Med. 2002;(3):265-275.

19. Dean AG, Sullivan KM, Soe MM. OpenEpi: Open Source Epidemiologic Statistics for Public Health, Version 2.3.1. http://www.OpenEpi.com. Accessed June 1, 2012.

20. Mitchell S, Ogilvie G, Steinberg M, Sekikubo M, Biryabarema C, Money D. Assessing women's willingness to collect their own cervical samples for HPV testing as part of the ASPIRE cervical cancer screening project in Uganda. Int J Gynaecol Obstet. 2011;14(2):111-115.

21. van de Wijgert J, Altini L, Jones H, et al. Two methods of self-sampling compared to clinician sampling to detect reproductive tract infections in Gugulethu, South Africa. Sex Transm Dis. 2006;33:516-523.

22. Lack N, West B, Jeffries D, et al. Comparison of non-invasive sampling methods for detection of HPV in rural African women. Sex Transm Infect. 2005;81:239-241.

23. Barata PC, Mai V, Howlett R, Gagliardi AR, Stewart DE. Discussions about self-obtained samples for HPV testing as an alternative for cervical cancer prevention. J Psychosom Obstet Gynaecol. 2008;29(4): 251-257.

24. Sanchaisuriya P, Pengsaa P, Sriamporn S, et al. Experience with a self-administered device for cervical cancer screening by Thai women with different educational backgrounds. Asian Pac J Cancer Prev. 2004;5(2):144-150.

25. Nobbenhuis MA, Helmerhorst TJ, van den Brule AJ, et al. Primary screening for high risk HPV by home obtained cervicovaginal lavage is an alternative screening tool for unscreened women. J Clin Pathol. 2002;55(6):435-439.

26. Institut National de la Statistique (INS) et ORC Macro. 2004. Enquête Démographique et de Santé du Cameroun 2004. Caractéristiques des femmes et des hommes enquêtés. [Demographic and Health Survey of Cameroon 2004. Characteristics of women and men surveyed]. Available from: http://www.measuredhs.com/pubs/pdf/FR163/03chapitre03.pdf. Accessed March 1, 2012. French.
International Journal of Women's Health

\section{Publish your work in this journal}

The International Journal of Women's Health is an international, peerreviewed open-access journal publishing original research, reports, editorials, reviews and commentaries on all aspects of women's healthcare including gynecology, obstetrics, and breast cancer. The manuscript management system is completely online and includes

\section{Dovepress}

a very quick and fair peer-review system, which is all easy to use. Visit http://www.dovepress.com/testimonials.php to read real quotes from published authors. 